\title{
Roadkill risk and population vulnerability in European birds and mammals
}

Article

Accepted Version

Grilo, C., Koroleva, E., Andrasik, R., Bil, M. and GonzalezSuarez, M. (2020) Roadkill risk and population vulnerability in European birds and mammals. Frontiers in Ecology and the Environment, 18 (6). pp. 323-328. ISSN 1540-9295 doi: https://doi.org/10.1002/fee.2216 Available at https://centaur.reading.ac.uk/89172/

It is advisable to refer to the publisher's version if you intend to cite from the work. See Guidance on citing.

To link to this article DOI: http://dx.doi.org/10.1002/fee.2216

Publisher: Ecological Society of America

All outputs in CentAUR are protected by Intellectual Property Rights law, including copyright law. Copyright and IPR is retained by the creators or other copyright holders. Terms and conditions for use of this material are defined in the End User Agreement.

\section{www.reading.ac.uk/centaur}

\section{CentAUR}

Central Archive at the University of Reading 
Reading's research outputs online 


\title{
ROADKILL RISK AND POPULATION VULNERABILITY IN EUROPEAN BIRDS AND MAMMALS
}

\author{
Clara Grilo ${ }^{1,2 *}$, Elena Koroleva ${ }^{3}$, Richard Andrášik², Michal Bíl², Manuela González-Suárez ${ }^{4}$ \\ ${ }^{1}$ CESAM, Centre for Environmental and Marine Studies (CESAM/UA), Faculdade de Ciências da Universidade de \\ Lisboa, 1749-016 Lisboa, Portugal \\ ${ }^{2}$ CDV - Transport Research Centre, Líšeňská 33a, 63600 Brno, Czech Republic \\ ${ }^{3}$ Department of Biogeography, Faculty of Geography, Moscow State Lomonosov University, 119991 Moscow, Russia \\ ${ }^{4}$ Ecology and Evolutionary Biology, School of Biological Sciences, University of Reading, Reading, UK \\ *Corresponding Author
}

Keywords: roadkill rates, life traits, trait-based models, spatially explicit models

\begin{abstract}
Roads represent a threat to biodiversity, primarily through increased mortality from collisions with vehicles. Although estimating roadkill rates is an important first step, how roads affect long-term population persistence must also be assessed. We developed a trait-based model to predict roadkill rates for terrestrial bird and mammalian species in Europe and used a generalized population model to estimate their long-term vulnerability to road mortality. We found that $\sim 194$ million birds and $\sim 29$ million mammals may be killed each year on European roads. The species that were predicted to experience the highest mortality rates due to roads were not necessarily the same as those whose long-term persistence was most vulnerable to road mortality. When evaluating which species or areas could be most affected by road development projects, failure to consider how roadkill affects populations may result in misidentifying appropriate targets for mitigation.
\end{abstract}

\section{Introduction}

Roads are a threat for both endangered and common species mainly due to additional mortality from collisions with vehicles (Rytwinski and Fahrig 2015). There is growing evidence that road mortality could be leading many local populations towards extirpation unless mitigation actions are applied (Ceia-Hasse et al. 2017). A better understanding of how mortality from collisions with vehicles affects biodiversity is urgently needed, which we contend requires two steps. First, the number of animals killed on roads must be quantified; the species that are at greater risk from roads and the regions that are particularly dangerous to wildlife should be identified. Second, the effects of road-associated mortality on species' population size, spatial distribution, and long-term persistence must be determined.

We present a new framework for evaluating how roads affect biodiversity, considering both potential roadkill risk and population vulnerability for terrestrial bird and mammal species in Europe. Road densities in Europe are among the world's highest (Meijer et al. 2018); currently, 50\% of the European continent is within $1.5 \mathrm{~km}$ of paved roads and railways, which may contribute to declines in bird and mammal populations (Torres et al. 2016). Our proposed framework consists of two steps. First, we developed a predictive model of roadkill rates in Europe, based on diverse species traits that allowed us to predict rates for all species and to map potential roadkill incidence. Second, we applied a 
generalized theoretical population model to calculate species-specific vulnerability based on road density thresholds beyond which local populations may not persist; this model therefore helps to identify which species and areas are most susceptible to long-term negative effects from roads. The results of our analysis could inform the development of effective road management and mitigation strategies in Europe.

\section{Material and Methods}

\section{Data compilation}

Between April and June 2018, we conducted a systematic search for scholarly papers published in peer-reviewed journals and the gray literature that included road surveys in Europe (see WebPanel 1 for more details). Only systematic surveys were included in our analysis, with the exception of surveys involving large mammals, for which most records came from non-systematic surveys; these were assumed to be comparable due to the high detectability of large mammalian roadkill. Studies published between 2000 and 2018 that sampled a minimum of $5 \mathrm{~km}$ of paved roads and had a maximum survey interval (sampling frequency; that is, how often roads were monitored for roadkill presence) of 30 days and a minimum survey period (the total duration of the study) of 3 months were included in the analysis. We estimated roadkill rates as the number of individuals killed per kilometer of road per year for each species (WebPanel 1). Using survey intervals, we corrected the roadkill rates to account for time on the pavement, based on Santos et al. (2011). For non-systematic survey data for large mammals, we assumed a high level of detectability for the animals and therefore considered these survey intervals to be more or less equivalent to a daily survey interval; as such, no correction was applied to the roadkill rate (ie correction factor $=1$; WebPanel 1 ).

A complete list of wild bird and mammal species in Europe was obtained from the BirdLife website (https://bit.ly/2Mk4zns) and the European Red Lists of species website (https://bit.ly/3eHJkla) (WebPanel 1). We compiled 16 life-history traits for bird species and 17 life-history traits for mammal species (WebTable 1, following González-Suárez et al. [2018]). Human exploitation was hypothesized to lower roadkill rates because species historically persecuted by humans tend to avoid developed areas (WebTable 1; Laurance et al. 2006). Two additional demographic parameters - clutch/litter size and the number of clutches/litters per year - were included in the theoretical population model to define species' relative vulnerability to road impacts (WebTable 1). These data were obtained from published databases supplemented with an additional literature search to fill data gaps (WebTable 1).

\section{Predicting roadkill rates}

We followed the methods described in González-Suárez et al. (2018) for generating random forest regression trees (Cutler et al. 2007), a machine learning technique that uses bootstrapped data samples to construct multiple regression trees from which the importance of the predictors is defined (Breiman 2001). Because trait and demographic data were not available for all European bird and mammal species, we used statistical imputation methods based on random forest regression trees, which generate estimates for missing values using information from the existing data (Stekhoven and Bühlmann 2012). We generated 15 imputed datasets for each taxonomic group to capture uncertainty in the imputation process and to assess the sensitivity of the results, and then fitted trait-based random forest regression models separately for birds and mammals to explain empirical roadkill rates. The models used all available roadkill rates (ie multiple values per species) to capture the observed spatial and temporal variability in roadkill rates for each species. Predictors included in the models 
consisted of species trait data, characteristics of the study (survey location [latitude and longitude], and survey interval) to account for species abundance and detectability, and taxonomic order to account for evolutionary relationships. Fitted models were then used to predict roadkill rates for all bird and mammal species in Europe, based on their trait values and taxonomic order. To generate predictions for the whole of Europe, we defined $50-\mathrm{km} \times 50-\mathrm{km}$ grid cells covering the continent and simulated hypothetical surveys within each grid cell, with survey location (latitude and longitude) taken as the centroid of each grid cell and with the survey interval assumed to be equal to the median from the empirical data (use of different intervals did not qualitatively change the results). Because information concerning how roads influence behavior was not available for most species, road avoidance behavior could not be considered, and we therefore assumed that all bird and mammal species cross roads.

\section{Estimating long-term species vulnerability}

We estimated long-term vulnerability by comparing species-specific maximum road density thresholds (Max Road $_{\text {) }}$ above which long-term population persistence is unlikely. We calculated thresholds using the theoretical demographic model developed by Borda-de- Água et al. (2011), which models a landscape consisting of two basic habitat types: roads and non-roads. Non-road areas are assumed to be adequate for a given species' continued persistence and allow intrinsic positive growth rates, whereas road areas are assumed to be unsuitable habitat associated with rapid population declines (Pereira et al. 2004; Ceia-Hasse et al. 2017). The reaction- diffusion equation proposed by Skellam (1951; WebPanel 1) was derived to

$$
\operatorname{Max}_{\mathrm{Road}}=\frac{r_{1}}{r_{1}+\left|r_{0}\right|}
$$

(Equation 1),

where $r_{1}$ is the intrinsic population growth rate and $r_{0}$ is the rate of population decay on roads. We calculated $r_{1}$ with a simplified version of the Euler equation (Pereira and Daily 2006, WebPanel 1). Fifteen estimates of $r_{1}$ were obtained (one per imputed dataset) including: maturity age (yr), the number of female offspring in a clutch/litter (clutch/litter ${ }^{*} 0.5$, assuming equal sex ratio at birth), and the number of clutches/litters per year (reflecting the interval between reproductive events; WebTable 1). We use the equation described by Ceia-Hasse et al. (2017) to calculate:

$$
r_{0}=\frac{-\mu \times R M}{\text { year }}
$$

(Equation 2),

where $\mu$ is the annual natural mortality rate estimated for each species given its longevity (see WebTable 1) and $R M$ is a scaling factor for road mortality that assumes roads are unsuitable habitats where species persistence is not possible $(\mathrm{RM}=1000$ was the value assumed by Ceia-Hasse et al. 2017). Empirical data on RM are not available, but Ceia-Hasse et al. (2017) showed that while

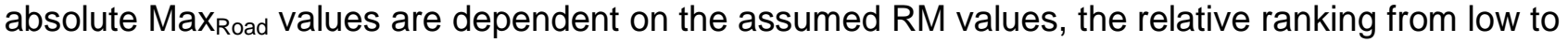
high Max $_{\text {Road }}$ within a group is constant. We therefore propose that this ranking provides a robust way to assess how long-term persistence may be impacted by roads, with those species that have low Max $_{\text {Road }}$ rankings being more vulnerable to roads in their habitat. We calculated the rank for each European bird and mammal, with those in the lowest $20^{\text {th }}$ percentile for each group considered most vulnerable. We performed a global sensitivity analysis to determine which model parameters most

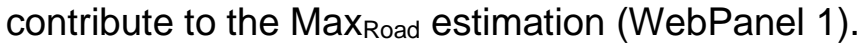

\section{Mapping roadkill incidence and critical areas for conservation}

We used the paved road network presented in Meijer et al. (2018), which includes 3,071,824 km of roads in Europe. All paved roads were treated as equivalent in the prediction of roadkill estimates; although roads vary in terms of traffic levels and characteristics, detailed information is not widely 
available, and there is no scientific consensus regarding how different types of roads and traffic intensity influence roadkill risk (see Bissonette and Kassar 2008; Grilo et al. 2015; Sadleir and Linklater 2016). As such, specific predictions based on road characteristics are not yet possible. Rather, our analysis generates values that reflect the average effect of different types of roads. We calculated the density of paved roads (kilometer of road per square kilometer of land area, or km $\mathrm{km}-2$ ) within each $50-\mathrm{km} \times 50-\mathrm{km}$ grid cell. The total number of individuals in each grid cell that could be killed on roads was estimated as the median predicted roadkill rate (across the 15 imputed datasets) for each species present in the cell, multiplied by the road density in the cell. We then mapped (1) areas of roadkill incidence reflecting the sum of predicted roadkill for birds and mammals, and (2) critical areas of impact representing the total number of vulnerable bird and mammal species in each grid cell. We tested the spatial match between the number of roadkill and the number of species vulnerable to roads using Spearman's correlation.

All datasets (roadkill rates and species traits) and output files (predicted roadkill rates and estimated Max $_{\text {Road) }}$ are available at https://doi.org/10.6084/m9.figsh are.79314 23.v2.

\section{Results}

We compiled data from 90 published roadkill surveys that collectively provided information from 24 European countries (nine for birds and 24 for mammals; WebPanel 1). From these surveys, we calculated 504 and 342 roadkill rates representing 140 bird species and 75 mammal species, respectively.

\section{Roadkill rates}

Random forest regression models explained $53.7 \%$ of the observed variance in roadkill rates for birds and $59.0 \%$ for mammals (Figure 1). In line with the findings of González-Suárez et al. (2018), survey location (latitude and longitude), survey interval, and taxonomic order were key predictors of roadkill rates for both birds and mammals (Figure 1). The traits that best explained roadkill rates for both birds and mammals were body mass, population density, longevity, and maturity age. Birds with small body size, high population density, greater longevity, an omnivorous diet or a diet predominantly composed of plants and seeds, and early maturity were more likely to experience road-associated mortality (WebFigure 1a). Similarly, mammals with small body size, small home range size, shorter longevity, high population density, and that are nocturnal and reach maturity at an early age were more likely to experience road-associated mortality (WebFigure $1 \mathrm{~b}$ ).
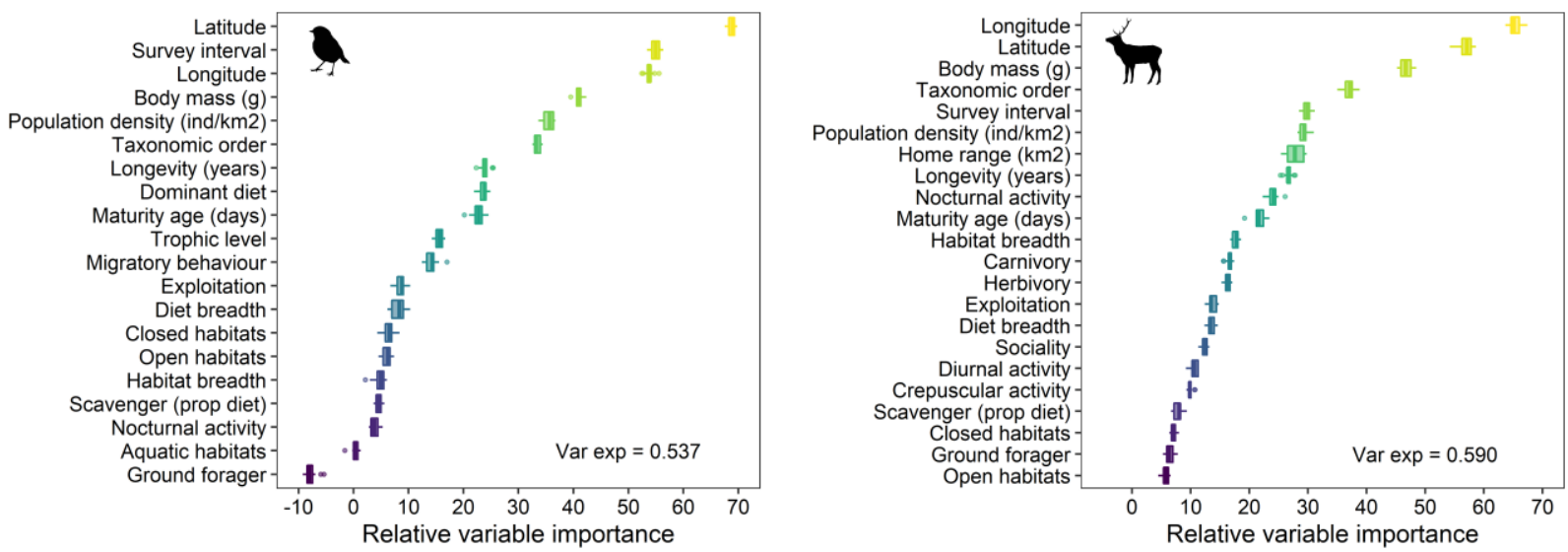

Figure 1 - Relative importance of variables associated with observed roadkill rates obtained from random forest regression models. Boxplots show results for the 20 and 22 survey and traits variables for birds and mammals, respectively. Vertical lines within boxes depict median values, and boxes represent the interquartile range (25th- 
75th percentiles). Whiskers (horizontal lines) represent the lowest and highest values if these are within $1.5 \times$ interquartile range; otherwise whiskers extend to $1.5 \times$ interquartile range, with higher and lower values shown as circles. Animal silhouettes from PhyloPic (http://phylo pic.org). Var exp = observed variance explained.

The lack of observed roadkill rates for six orders of bird species (Ciconiiformes, Gaviiformes, Phoenicopteriformes, Podicipediformes, Pterocliformes, and Suliformes) and two mammalian orders (Primates and Macroscelidea) prevented us from predicting roadkill for 17 bird and two mammal species found in Europe. In total, we predicted roadkill rates for 423 bird species and 212 mammal species within their European range in the $50-\mathrm{km} \times 50-\mathrm{km}$ grid cells. Predicted values generally matched the observed roadkill rates for species with empirical data although there was considerable variation (WebFigure 2). The highest median predicted roadkill rates were observed in blackbird Turdus merula (11.94 ind/km/year) and Soprano Pipistrelle bat Pipistrellus pygmaeus (1.76 ind $/ \mathrm{km} /$ year). We estimated that collisions with vehicles could result in the death of approximately 194 million individual birds and 29 million individual mammals on paved roads in Europe every year.

\section{Species vulnerable to roads}

The global sensitivity analysis revealed that age at maturity was the input variable that explained the

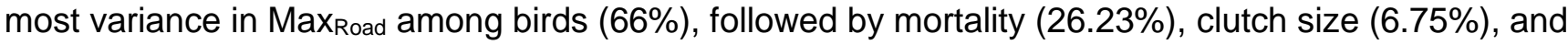
interval between births (0.22\%), with a coefficient of determination of $96 \%$. For mammals, mortality was the input variable that explained the most variance in MaxRoad (92.63\%), followed by maturity age $(2.99 \%)$, litter size $(2.96 \%)$, and interval between births (1.42\%), with a coefficient of determination of $95.7 \%$.

Hazel grouse (Bonasa bonasia) and russet ground squirrel (Spermophilus major) were the bird and mammal species ranked as most vulnerable to road impacts (lowest Max Road$_{\text {), }}$ respectively. Both are common in Europe and are classified as Least Concern by International Union for Conservation of Nature (IUCN) Red List of Threatened Species. The most vulnerable species currently listed as Threatened on the IUCN Red List were the red-knobbed coot (Fulica cristata; ranked $14^{\text {th }}$ out of 423 bird species), and the Balcan mole rat (Spalax graecus; ranked second out of 212 mammal species) and Podolian mole rat (Spalax zemni; ranked third out of 212 mammal species). Of the 84 birds and 42 mammals identified as vulnerable (in the lowest $20^{\text {th }}$ percentile), twenty (tean of each taxon) were classified as Threatened or Near Threatened on the IUCN Red List.

\section{Species and areas with high roadkill incidence and vulnerability to road impacts}

Species with higher roadkill rates were not always ranked as most vulnerable to road impacts (ie those for which road mortality is more likely to affect long-term persistence). For example, the house sparrow Passer domesticus had high roadkill rate projections (median $2.7 \mathrm{ind} . / \mathrm{km} / \mathrm{year}$ ), yet it was among the least vulnerable of the bird species (ranked $420^{\text {th }}$ out of 423 ); in contrast, roadkill rate projectsions for hazel grouse were low (median $0.2 \mathrm{ind} / \mathrm{km} / \mathrm{year}$ ), but it was the most vulnerable species (ranked first, with the lowest Max road). 


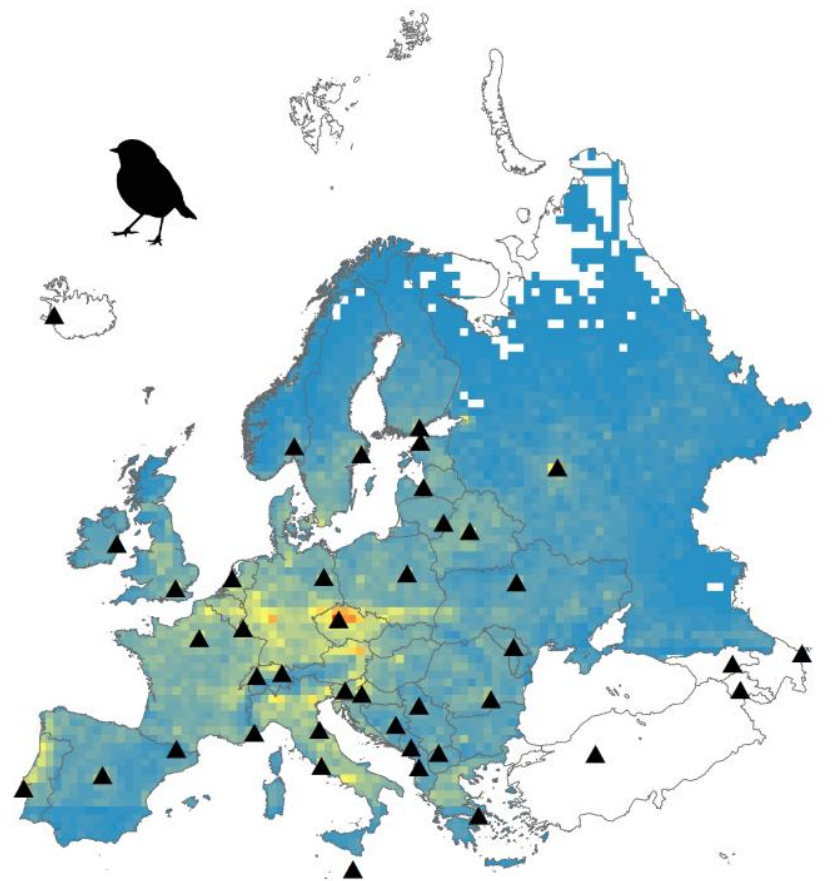

Numbers of roadkilled individuals

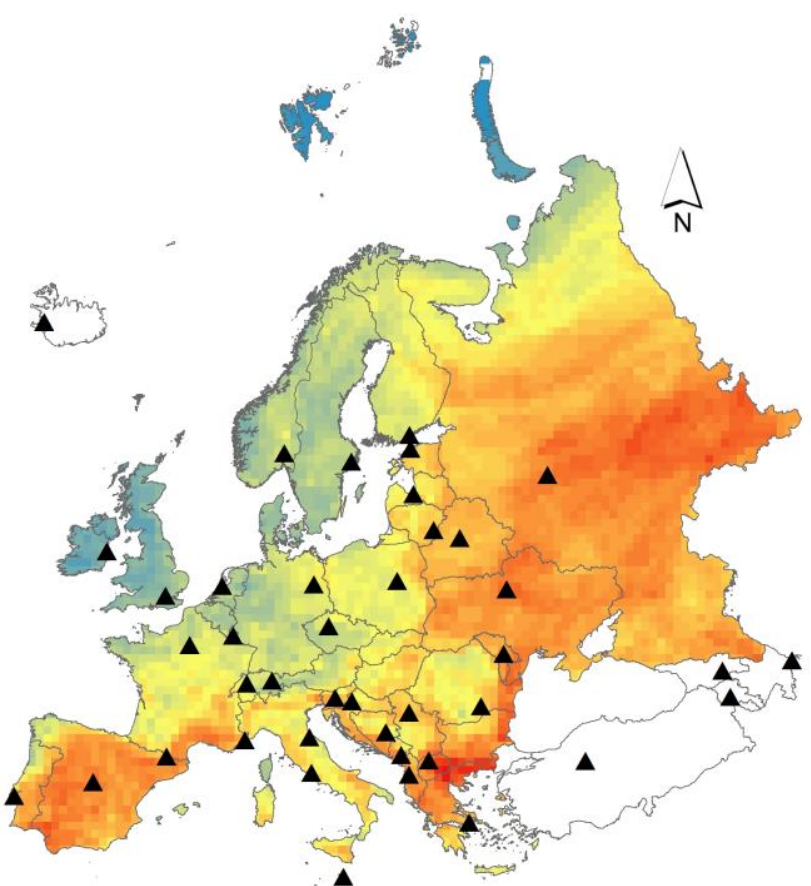

Number of vulnerable species

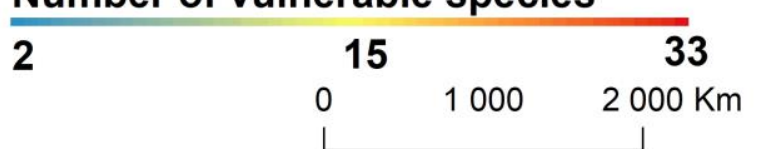

Figure 2 - Cumulative predicted number of birds killed on roads per year and number of vulnerable bird species (20th percentile) in each 50-km $\times 50-\mathrm{km}$ grid cell in Europe. Black triangles mark the locations of major cities.

Maps of roadkill incidence (cumulative roadkill rates) show considerable variation across regions, with the highest values for both birds and mammals occurring in Central Europe (Figures 2 and 3). Each year, more than 100,000 birds and more than 30,000 mammals were projected to occur as roadkill in areas representing approximately $10 \%$ and $3.5 \%$ of Europe, respectively. The spatial patterns were consistent using predicted roadkill rates based on upper and lower $95 \%$ confidence interval estimates (WebFigure 3, a and b). 

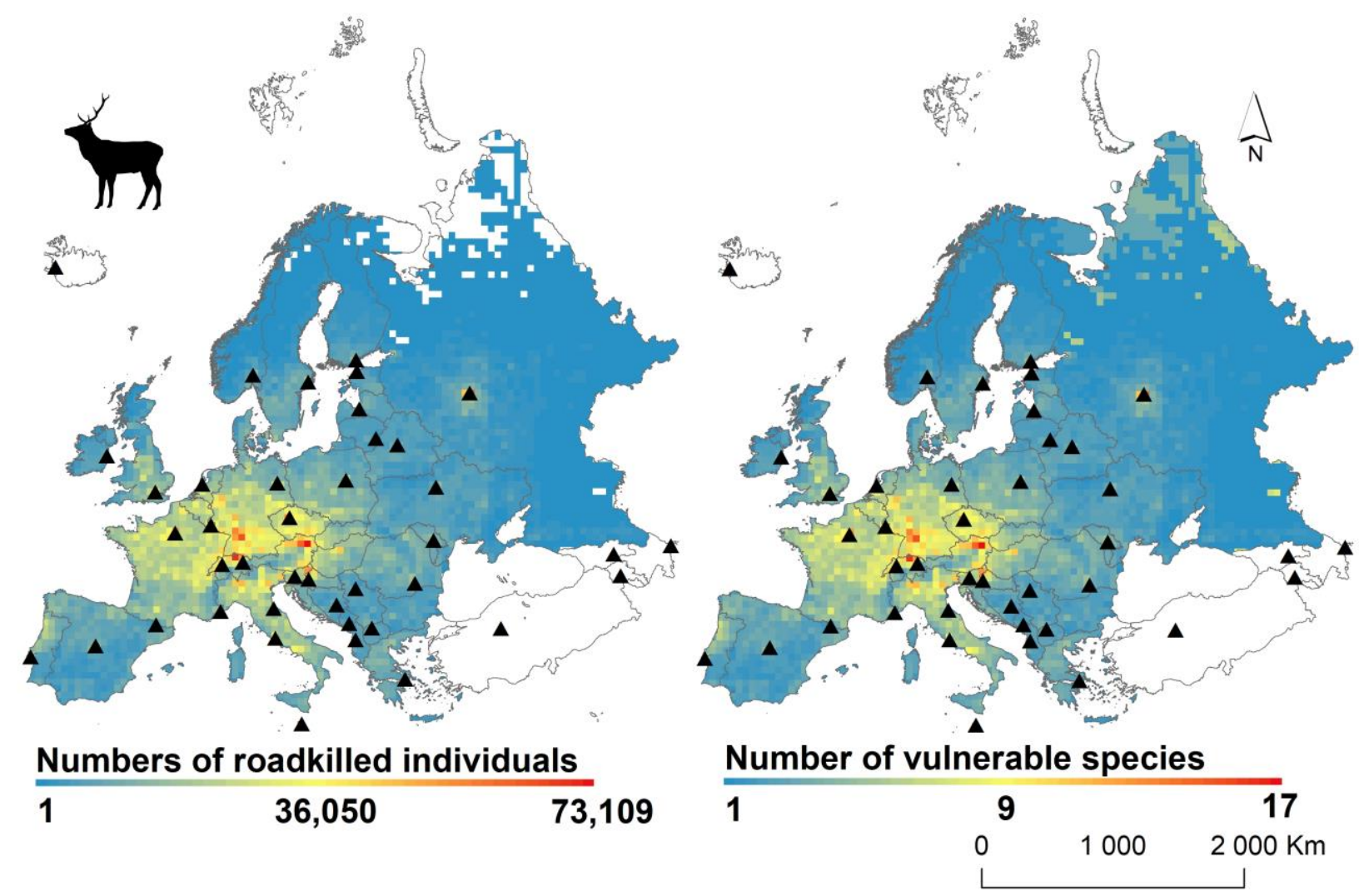

Figure 3 - Cumulative predicted number of mammals killed on roads per year and number of vulnerable mammal species (20th percentile) in each $50-\mathrm{km} \times 50-\mathrm{km}$ grid cell in Europe. Black triangles mark the locations of major cities.

The highest concentrations of vulnerable bird species were found in the lberian Peninsula, the Balkan Peninsula, and Eastern European countries, whereas vulnerable mammal species were concentrated in northern Spain, Italy, Austria, and the Balkan Peninsula (Figures 2 and 3). In most areas of Europe ( $89 \%$ of the grid cells) there were many (more than ten) vulnerable bird species, while only about onefifth of the region ( $21 \%$ of the grid cells) contained more than ten vulnerable mammal species. Critical area locations for birds and mammals were similar when the proportion of vulnerable species was considered (WebFigure $3 \mathrm{c}$ ). Weak correlations were detected between predicted roadkill rates and the estimated number of species vulnerable to roads $(r=-0.013$ and $r=0.49$ for birds and mammals, respectively). High values of roadkill for mammals and vulnerability for birds and mammals coincided with areas of high species richness (WebFigure $3 d$ ).

\section{Discussion}

Many wildlife species are under increasing pressure from additional mortality caused by road collisions (van der Ree et al. 2015). Understanding the mechanisms that drive species' vulnerability to road traffic is key to developing strategies that balance sustainable transportation with biodiversity conservation. However, relevant information - about how different species interact with roads, and how traffic patterns influence species risk and responses - is currently lacking. In addition, we do not have trait and demographic data for all species, and we lack improved population models that can 
directly integrate road mortality estimates to assess the persistence for diverse taxa. The framework presented here is an important first step toward estimating road impacts, but the results of our analysis must be interpreted with caution in light of data and model limitations. Nonetheless, we believe this approach is a crucial advance in road ecology, as it can be used to inform road planning, construction, and impact mitigation in Europe while recognizing the necessity of local studies and assessments for accurate estimates of road impacts on particular species in different areas.

\section{Roadkill risk}

Our results demonstrate the value of using trait-based models to assess roadkill risk. These models revealed, for example, that European species characterized by higher population densities, smaller body mass, and earlier maturity are at greater risk of being killed on roads. These traits likely reflect or are associated with higher local abundance (Blackburn and Lawton 1994), which previous studies have shown leads to higher roadkill rates (D'Amico et al. 2015). Estimating local abundance can be a more direct approach to assessing risk, but obtaining relevant information for numerous species across large areas is often not feasible due to financial and time constraints. Trait-based models represent an effective alternative approach to conducting initial risk assessments using currently available data.

Comparing our results to previous efforts linking traits and roadkill risk highlights the need for careful consideration of the unique characteristics of individual species, populations within a species, and discrete regions, because the idiosyncrasies of different populations and areas can result in considerable variation (Barthelmess and Brooks 2010; González-Suárez et al. 2018). Differences may also reflect variations in animal road avoidance behaviors and in driver attitudes among regions (Cook and Blumstein 2013; Jacobson et al. 2016). Incorporating such animal and human behavioral factors into future predictive models will help to further our understanding of the underlying drivers of roadkill risk in different areas.

Millions of individual birds and mammals are likely killed on European roads every year; for understudied species, the predictions of roadkill rates are especially concerning. We believe it is time to realize the potential of using readily available trait data to assess road risk, thereby advancing road ecology from a largely descriptive discipline toward becoming a more predictive one.

\section{Vulnerability to roadkill}

Our vulnerability ranking, based on road density thresholds, offers new information about the potential impacts of roads on a diverse range of European species, and suggests that impact is not always associated with higher observed or predicted roadkill risk. Even when both observed and predicted roadkill rates are extremely high, this source of mortality may not have a major effect on the long-term viability of large populations (Borda-de- Água et al. 2014). Conversely, even low roadkill rates may be detrimental to rare or very sensitive species (Ceia-Hasse et al. 2017).

We also found that road density thresholds can vary greatly among species. Previous studies have proposed general thresholds (eg $0.3 \mathrm{~km} \mathrm{~km}-2$ threshold for birds and mammals in Canada; Anderson et al. 2011); although our approach did not allow for absolute thresholds to be defined, the relative values varied substantially, indicating that differences among species must be taken into consideration. In addition, we found that roads can threaten local persistence in some species not traditionally considered as conservation priorities (ie those classified as Least Concern on the IUCN Red List). Roads and traffic may provide the final push toward extinction for species already imperiled 
by other factors but could also be the beginning of the path toward extinction for relatively common species.

\section{Challenges on future road planning}

The framework presented here allows for the generation of more predictive assessments of roadkill rates and offers insights that will aid in the development of infrastructure planning strategies in Europe that incorporate actions to mitigate the effects of roads on wildlife. Common species and species of Least Concern are impacted by roads in many parts of Europe that are also inhabited by numerous vulnerable bird and mammal species. On the basis of these findings, we recommend that efforts aimed at local assessments and protection of vulnerable species be prioritized, particularly in regions with high road densities (WebFigure 3e).

An additional 25 million $\mathrm{km}$ of paved roads are expected to be constructed worldwide by 2050 (Laurance et al. 2014). Projections indicate that the greatest increases in road development will occur in the US, India, Australia, Canada, and China, but also in areas of high global conservation interest, such as the Democratic Republic of Congo, Nigeria, Papua New Guinea, and Brazil (Meijer et al. 2018). Our macroecological assessment of risk and potential impact can be broadly applied to anticipate potential future losses, provide guidance for national road planning, support the definition of target areas for further testing and assessment at a finer-scale resolution, and ultimately contribute to the prioritization of site-specific areas where mitigation would be most beneficial.

\section{Acknowledgments}

This study was performed on behalf of the International Mobility of Researchers in CDV - Transport Research Centre (\#CZ.0 2.2.69/0.0/0.0/16_027/0008352). We thank L Borda-de- Água and HM Pereira for their comments on the study, $\mathrm{V}$ Cicha for information on the European road network and assistance with GIS, and J Kubeček for organizing the life-trait databases. We also thank the Fundação da Ciência e Tecnologia/Ministério da Ciência, Tecnologia e Ensino Superior for the financial support to CESAM (UIDP/50017/2020+UIDB/50017/2020), through national funds.

\section{References}

Anderson SC, Farmer RG, Ferretti F et al. 2011. Correlates of Vertebrate Extinction Risk in Canada. BioScience 61: 538-549.

Barthelmess EL and Brooks MS. 2010. The influence of body-size and diet on roadkill trends in mammals. Biodivers Conserv 19: 1611-1629.

Bissonette JA and Kassar CA. 2008. Locations of deer-vehicle collisions are unrelated to traffic volume or posted speed limit. Human-Wildlife Conflicts 2:122-130.

Blackburn TM and Lawton JH. 1994. Population abundance and body size in animal assemblages. Phil Trans Roy Soc B 343:33-39.

Borda-de-Agua L, Navarro L, Gavinhos C and Pereira HM. 2011. Spatio-temporal impacts of roads on the persistence of populations: analytic and numerical approaches. Landscape Ecol 26:253-265.

Borda-de-Água L, Grilo C and Pereira HM. 2014. Modeling the impact of road mortality on barn owl (Tyto alba) populations using age-structured models. Ecol Model 276:29-37.

Breiman L. 2001. Random Forests. Mach Learn 45:5-32.

Ceia-Hasse A, Borda-de-Água L, Grilo C and Pereira HM. 2017. Global exposure of carnivores to roads. Global Ecol Biogeogr 26:592-600.

Cook TC and Blumstein DT. 2013. The omnivore's dilemma: diet explains variation in vulnerability to vehicle collision mortality. Biol Conserv 167:310-315. 
Cutler DR, Edwards TC, Beard KH, Cutler A, Hess KT, Gibson J and Lawler JJ. 2007. Random forests for classification in ecology. Ecology 88:2783-2792.

D’Amico M, Román J, de Los Reyes, Revilla E 2015. Vertebrate road-kill patterns in Mediterranean habitats: Who, when and where. Biol Conserv 191: 234-242.

Grilo C, Zanchetta Ferreira F and Revilla E. 2015. No evidence of a threshold in traffic volume affecting road-kill mortality at a large spatio-temporal scale. Environ Impact Assess Rev 55:54-58.

González-Suárez M, Zanchetta Ferreira F and Grilo C. 2018. Spatial and species-level predictions of road mortality risk using trait data. Global Ecol Biogeogr 27:1093-1105.

Jacobson SL, Bliss-Ketchum LL, de Rivera CE and Smith WP. 2016. A behavior-based framework for assessing barrier effects to wildlife from vehicle traffic volume. Ecosphere 7:e01345.

Laurance WF, Croes BM, Tchignoumba L, Lahm SA, Alonso A, Lee ME, Campbell P and Ondzeano C. 2006. Impacts of roads and hunting on central African rainforest mammals. Conserv Biol 20: 1251-1261.

Laurance WF, Clements GR, Sloan S, et al. 2014. A global strategy for road building. Nature 513:229-239.

Meijer JR, Huijbregts MAJ, Schotten KCGJ and Schipper AM. 2018. Global patterns of current and future road infrastructure. Environ Res Lett 13:064006.

Pereira HM, Daily GC and Roughgarden J. 2004. A framework for assessing the relative vulnerability of species to land-use change. Ecol Appl 14:730-742.

Pereira HM and Daily GC. 2006. Modeling biodiversity dynamics in countryside landscapes. Ecology 87:18771885.

Rytwinski T and Fahrig L. 2015. The Impacts of Roads and Traffic on Terrestrial Animal Populations. In: van der Ree R, Smith D, Grilo C (Eds) Handbook of Road Ecology. John Wiley \& Sons.

Sadleir RFMS and Linklater WL. 2016. Annual and seasonal patterns in wildlife road-kill and their relationship with traffic density. New Zeal J Zool 43:275-291.

Santos SM, Carvalho F and Mira A. 2011. How Long Do the Dead Survive on the Road? Carcass Persistence Probability and Implications for Road-Kill Monitoring Surveys. PLoS ONE 6(9): e25383.

Seiler A 2003. The toll of the automobile: wildlife and roads in Sweden. PhD thesis. Swedish University of Agricultural Sciences.

Skellam JG.1951. Random dispersal in theoretical populations. Bull Math Biol 53:135-165.

Stekhoven DJ and Bühlmann P. 2012. MissForest-non-parametric missing value imputation for mixed-type data. Bioinformatics 28:112-118.

Torres A, Jaeger JAG and Alonso JC. 2016. Assessing large-scale wildlife responses to human infrastructure development. Proc Natl Acad Sci USA 113:8472-8477.

van der Ree R, Smith D, Grilo C (Eds) Handbook of Road Ecology. John Wiley \& Sons. 

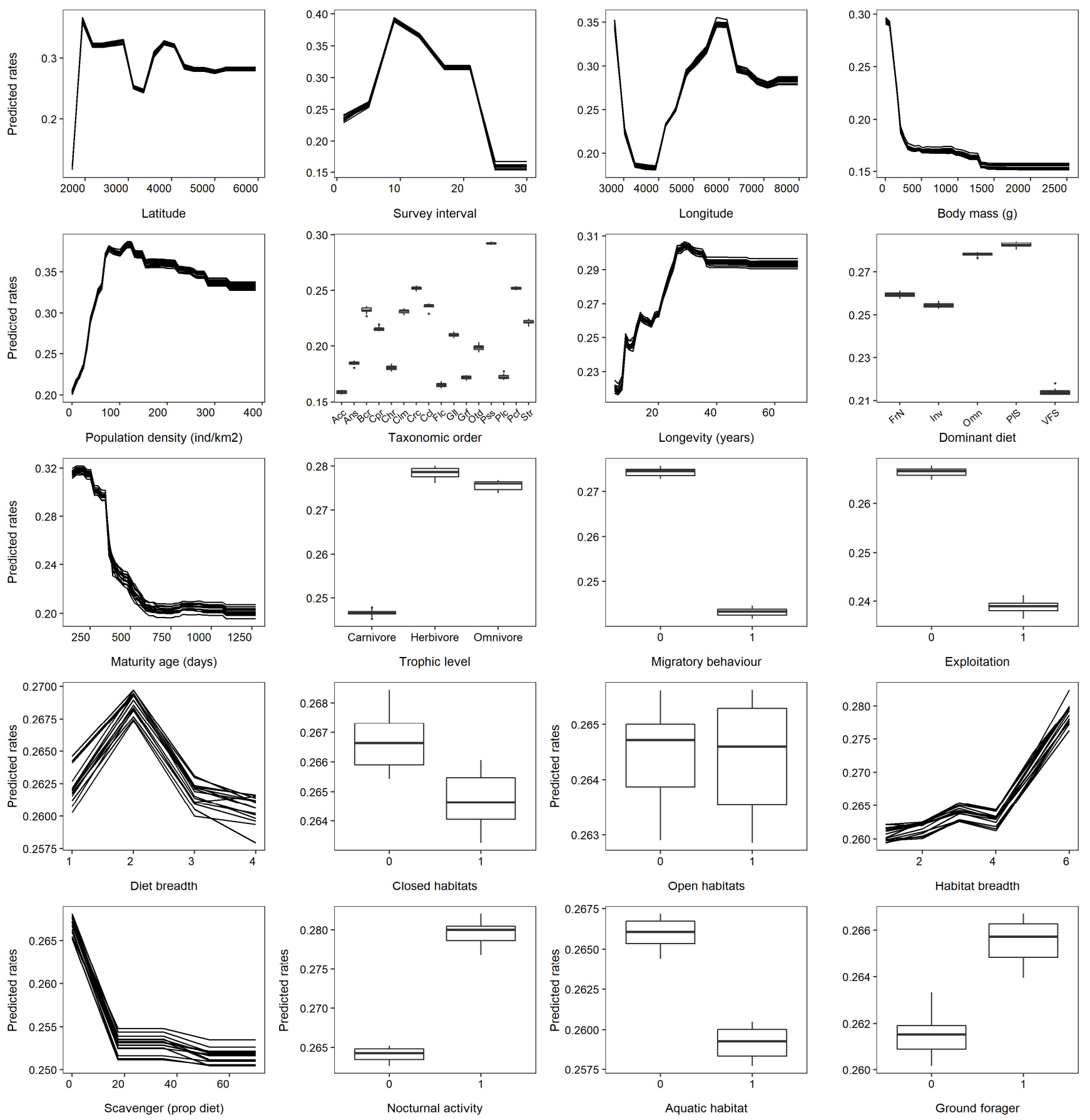

WebFigure 1a. Partial dependence plots showing the effects of the tested variables on predicted roadkill rates for birds, presented in order of relative importance for the model: Latitude, Survey interval, Longitude, Body mass, Population density, Taxonomic order (Acc: Accipitriformes; Ans: Anseriformes; Bcr: Buceriformes; Cpr: Caprimulgiformes; Chr: Charadriiformes; Clm: Columbiformes; Crc: Coraciiformes; Ccl: Cuculiformes; Flc: Falconiformes; Gll: Galliformes; Grf: Gruiformes; Otd: Otidiformes; Pss: Passeriformes; Plc:

Pelecaniformes; Pcf: Piciformes; Str: Strigiformes), Longevity, Dominant diet, Maturity age, Trophic level, Migratory behavior, Exploitation, Diet breadth, Closed habitats, Open habitats, Habitat breadth, Scavenger, Nocturnal activity, Aquatic habitats, and Ground forager. 

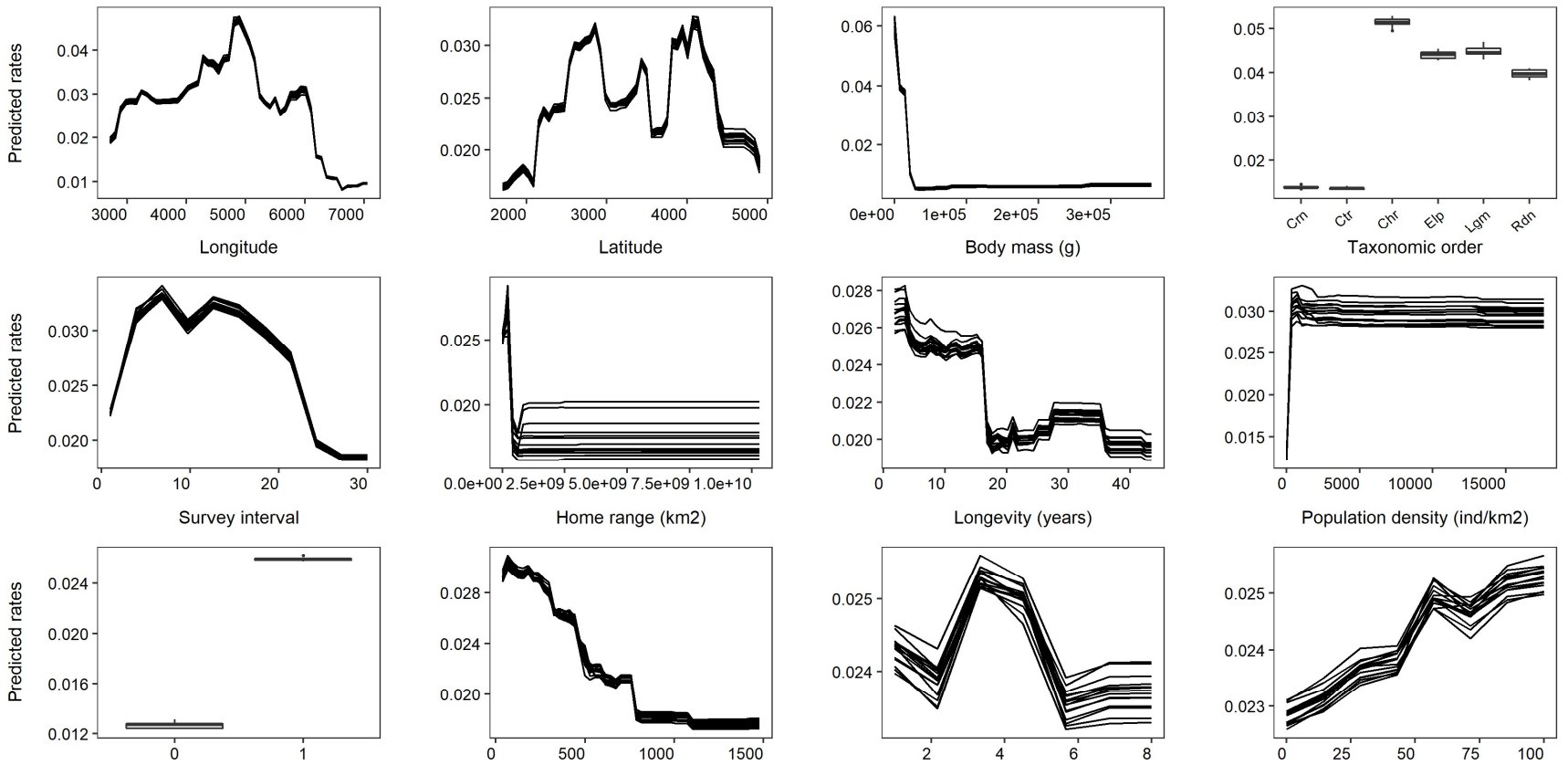

Home range $(\mathrm{km} 2$
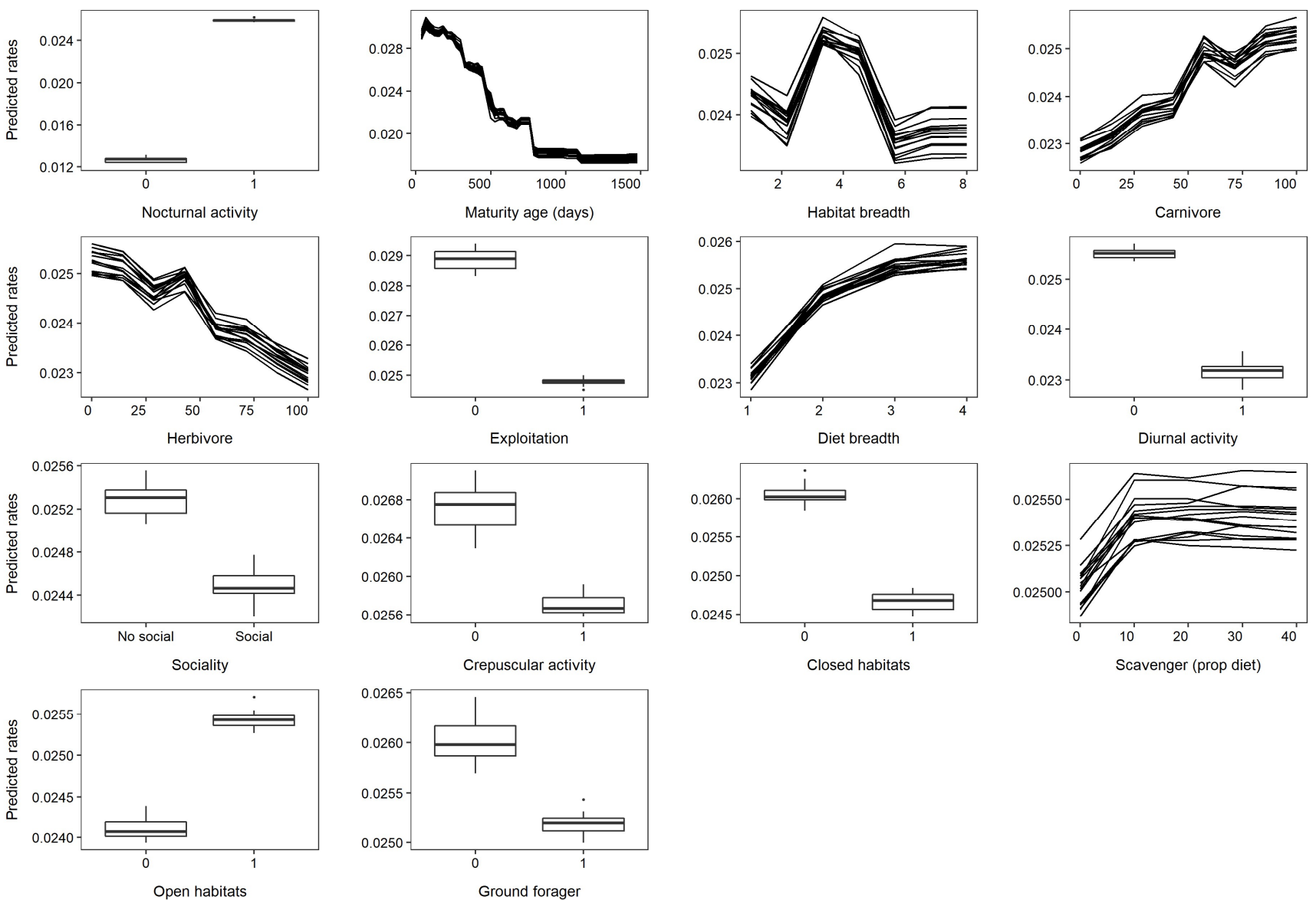

WebFigure 1b. Partial dependence plots showing the effects of the tested variables on predicted roadkill rates for mammals, presented in order of relative importance for the model: Longitude, Latitude, Body mass, Taxonomic order (Cm: Carnivora; Ctr: Cetartiodactyla; Chr: Chiroptera; Elp: Eulipotyphla; Lgm: Lagomorpha; Rdn: Rodentia), Survey interval, Home range, Longevity, Population density, Nocturnal activity, Maturity age, Habitat breadth, Carnivore, Herbivore, Exploitation, Diet breadth, Diurnal activity, Sociality, Crepuscular activity, Closed habitats, Scavenger, Open habitats, and Ground forager. 


\section{Grilo et al. - Supporting Information}
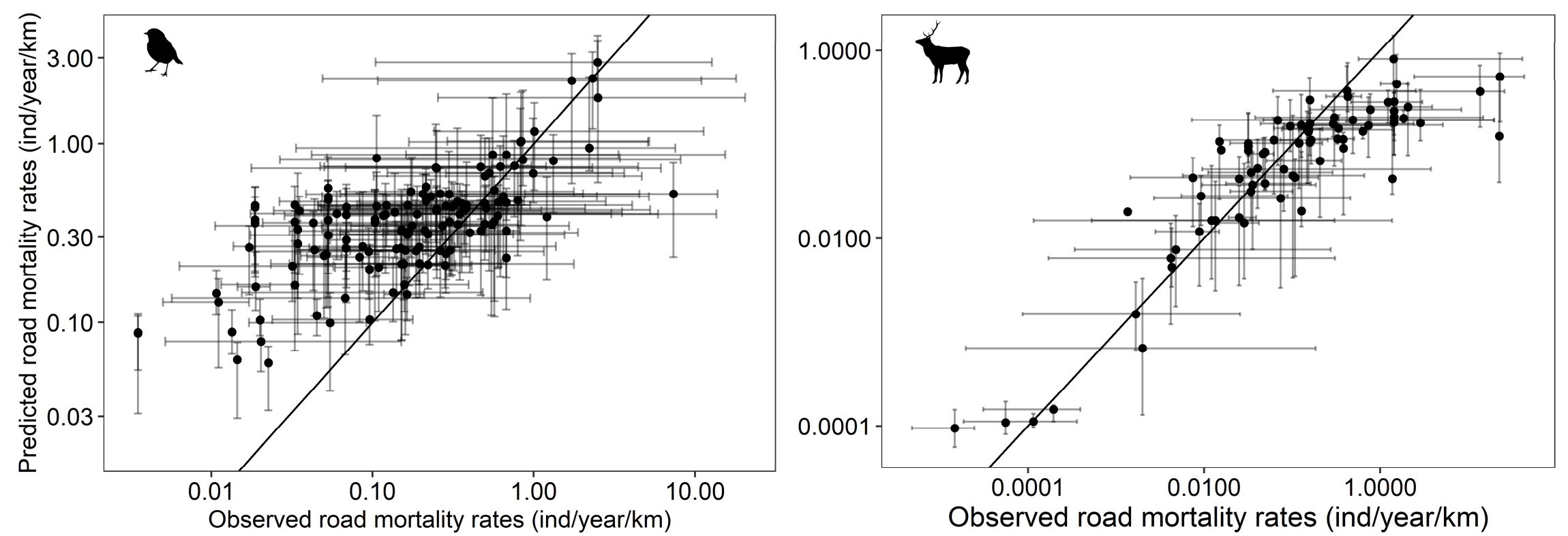

WebFigure 2. Predicted and observed road mortality rates for 140 bird and 75 mammal species. Solid circles represent the median value from all surveys for empirical data and across all predicted locations (that is, locations within grid cells) for predicted rates. Error bars represent $95 \%$ confidence intervals (CI) for observed and predicted values. Diagonal line indicates a 1:1 relationship.

A Caravaggi (robin); CC BY-NC-SA 3.0

S Traver (deer) 
(a)

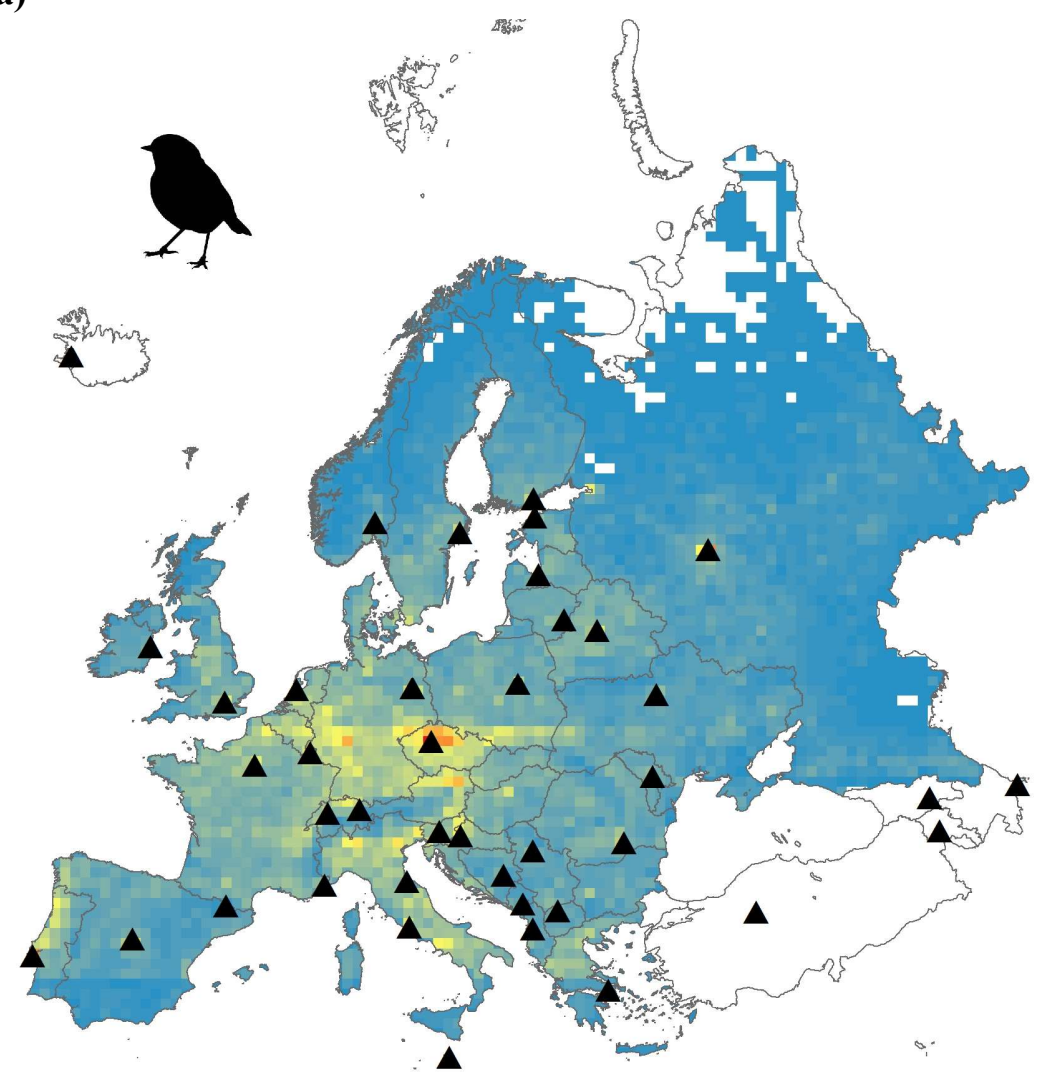

Number of roadkilled individuals (lower $95 \% \mathrm{CI}$ )

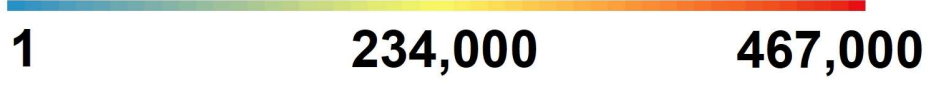

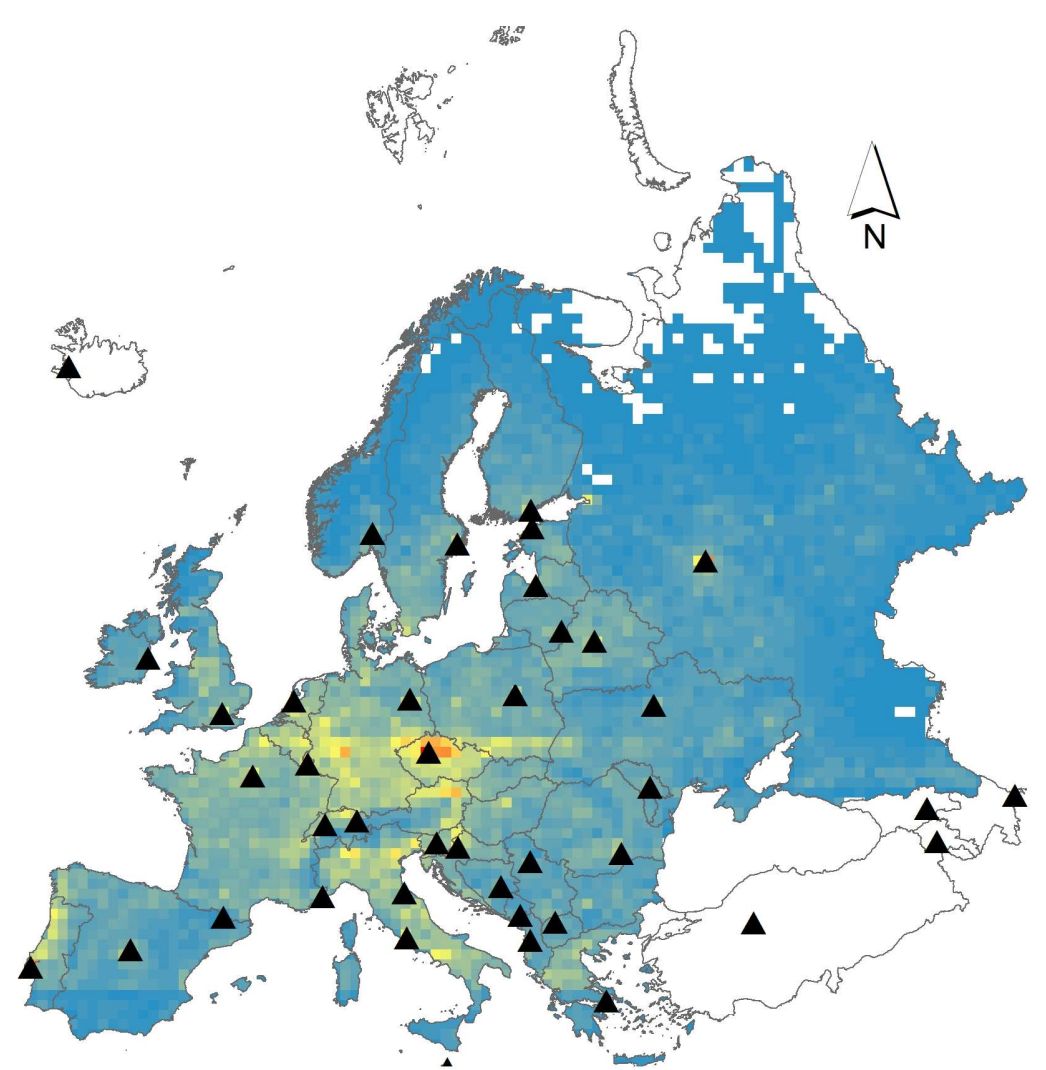

Number of roadkilled individuals (upper $95 \% \mathrm{CI}$ )

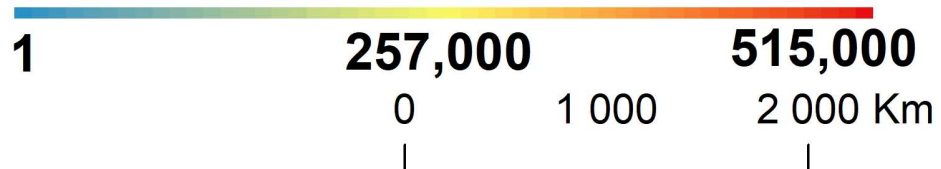


(b)
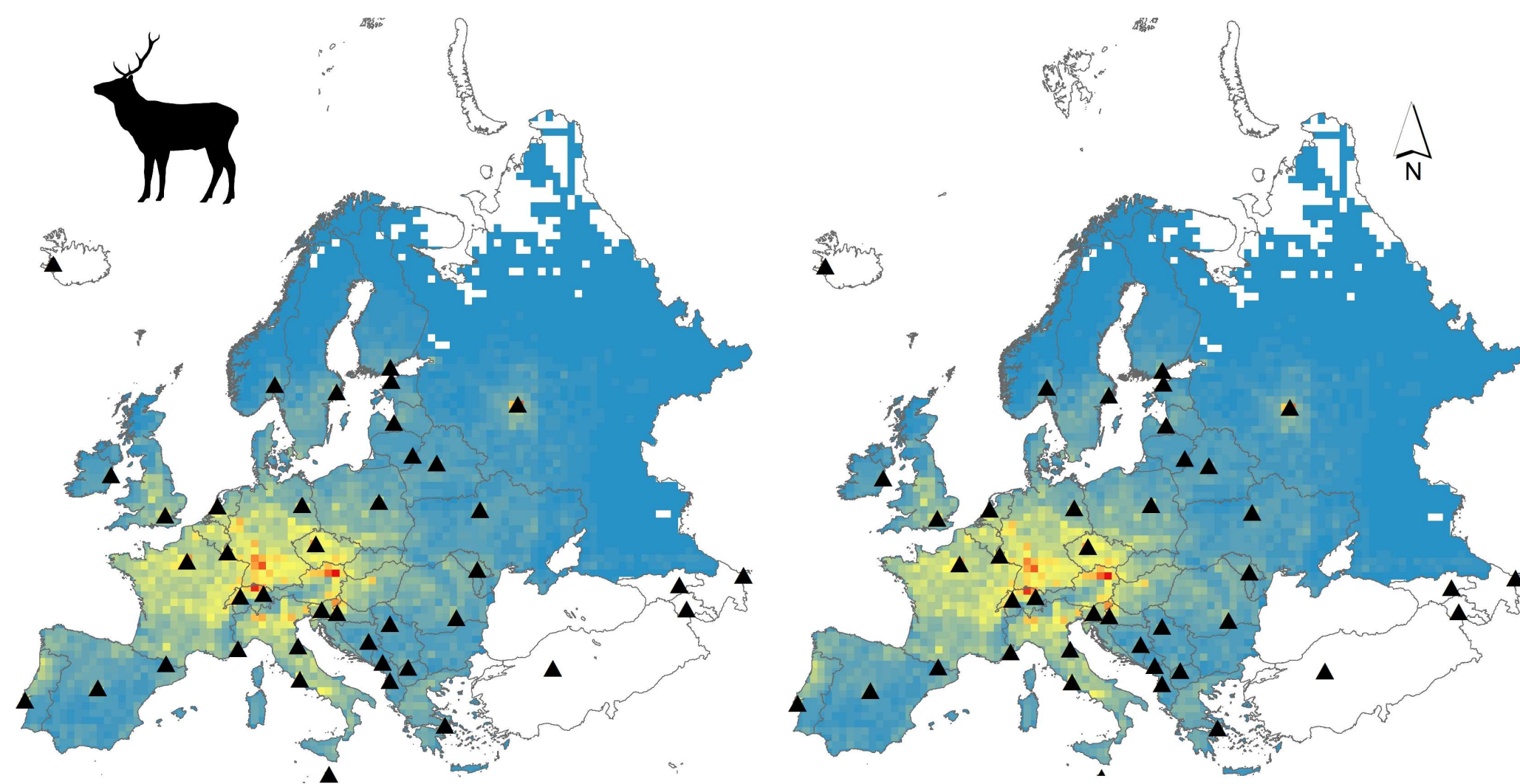

Number of roadkilled individuals (lower $95 \% \mathrm{Cl}$ )

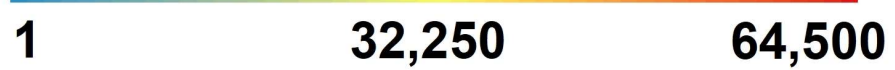

Number of roadkilled individuals (upper $95 \% \mathrm{Cl}$ )

\begin{tabular}{cccc}
$\mathbf{4 1 , 2 7 7}$ & & $\mathbf{8 3 , 3 5 4}$ \\
0 & 1000 & $2000 \mathrm{Km}$ \\
& & & \multicolumn{1}{l}{}
\end{tabular}


(c)

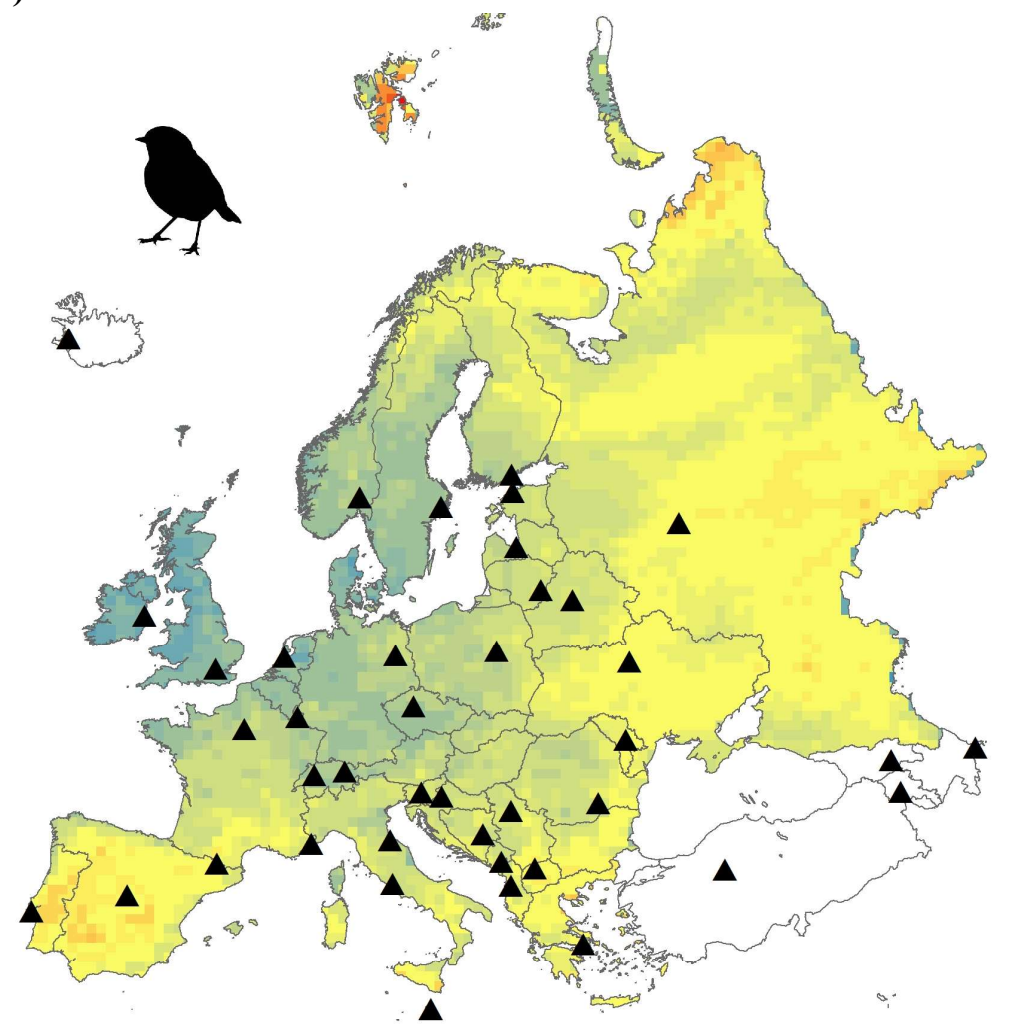

Proportion of vulnerable birds 1

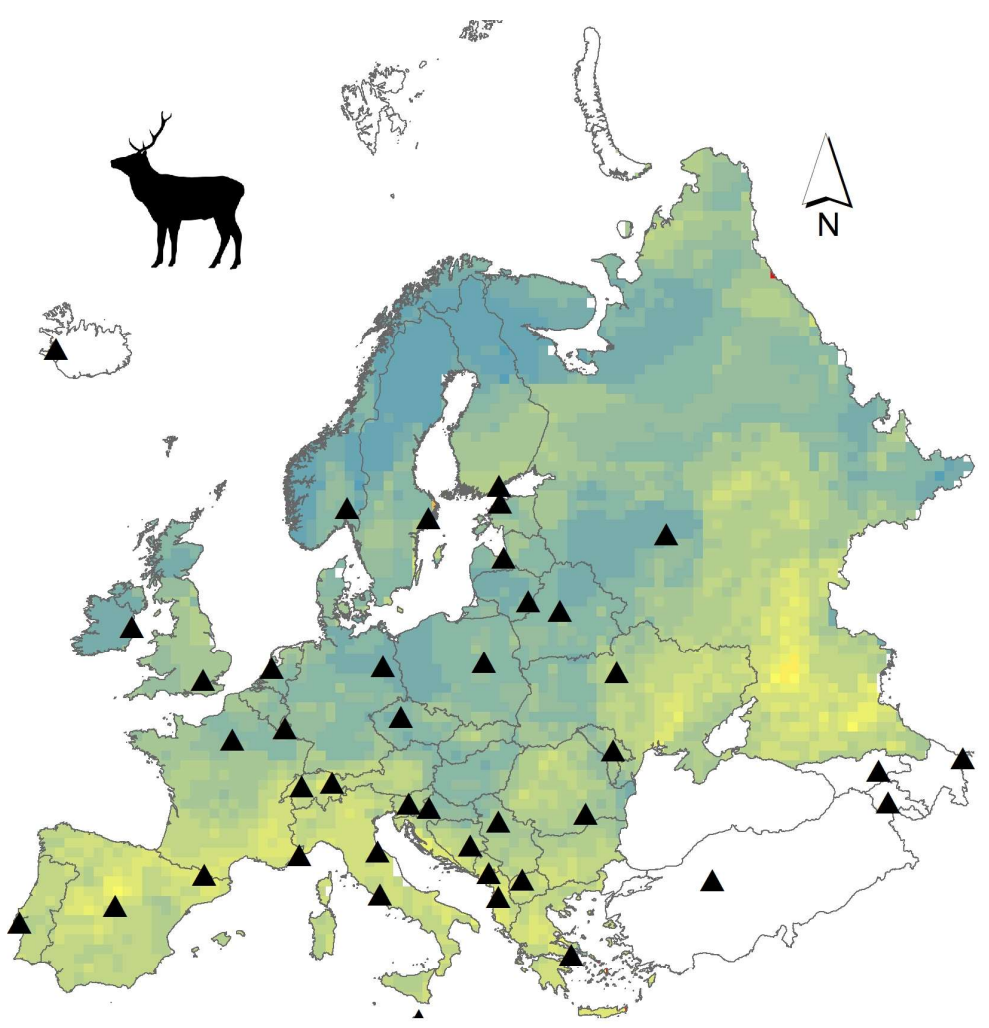

Proportion of vulnerable mammals

$1 \quad 0^{\mathbf{2 5}} \quad 1000 \quad 2000 \mathrm{Km}$


(d)

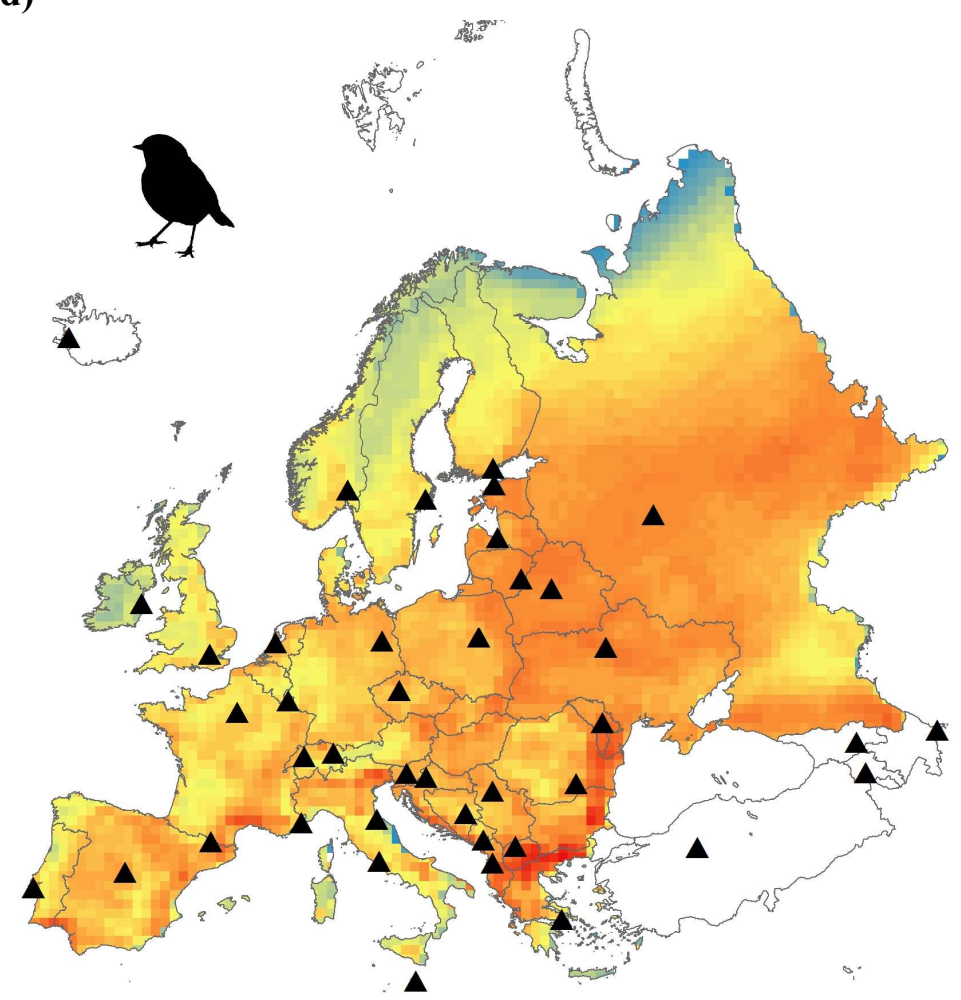

Total number of bird species

3

114

232

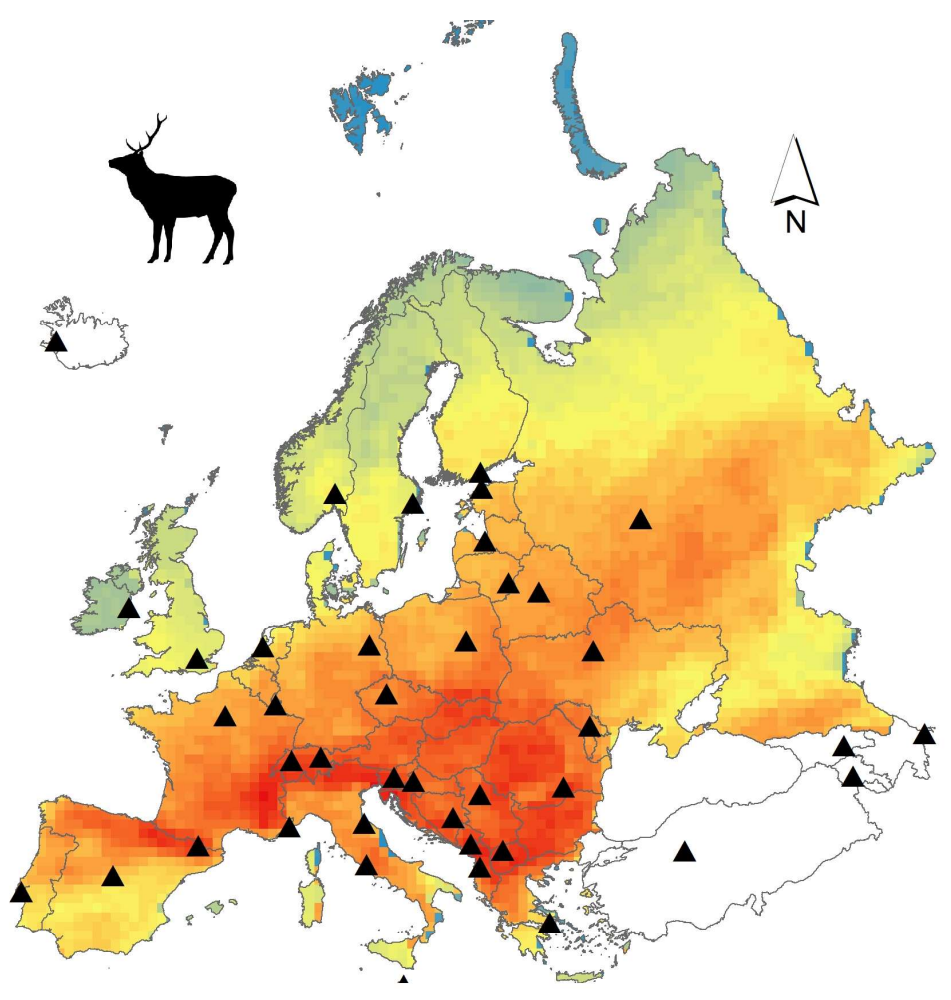

Total number of mammal species

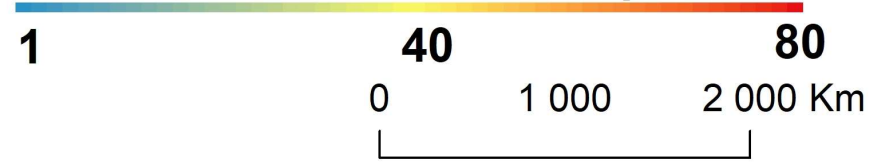


(e)

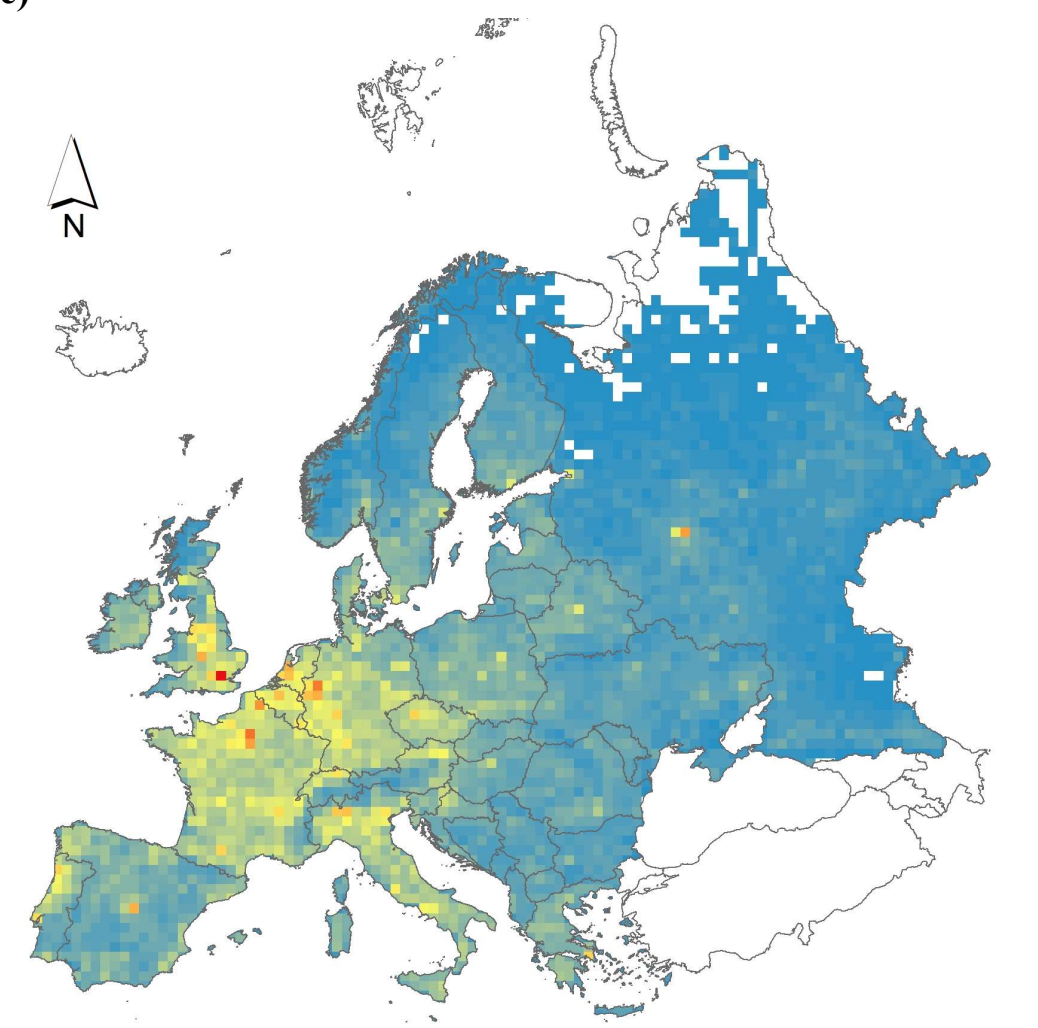

\section{Road density $(\mathrm{km} / \mathrm{km} 2)$}

\begin{tabular}{llll}
\hline $\mathbf{0 . 0 0 0 4}$ & $\mathbf{1 . 2 3}$ & $\mathbf{2 . 4 5 7}$ \\
& 0 & $1000 \quad 2000 \mathrm{Km}$
\end{tabular}

WebFigure 3. (a) Cumulative predicted roadkilled individuals per year for birds (with upper and lower 95\% CI). (b) Cumulative predicted roadkilled individuals per year for mammals (with upper and lower 95\% CI). (c) Proportion of vulnerable species for birds and mammals (number of species within the 20th percentile divided by the total number of species). (d) Species richness (total number of bird and mammal species in Europe). (e) Road density (paved roads) in $\mathrm{km} \mathrm{km}^{-2}$.

A Caravaggi (robin); CC BY-NC-SA 3.0

S Traver (deer) 


\section{Grilo et al. - Supporting Information}

WebTable 1. Definitions and data sources for the species traits considered as predictors of road mortality in Europe

\begin{tabular}{|c|c|c|c|c|}
\hline Species trait & Definition & Units & Classes & Main data source \\
\hline Body mass & $\begin{array}{l}\text { Geometric mean of average body mass values of individual adults } \\
\text { provided for both sexes }\end{array}$ & $\mathrm{g}$ & - & Wilman et al. (2014) \\
\hline Maturity age & $\begin{array}{l}\text { The median number of days at which individual females reach sexual } \\
\text { maturity }\end{array}$ & days & - & Myhrvold et al. (2015) \\
\hline Longevity & The maximum value of longevity & years & - & Myhrvold et al. (2015) \\
\hline Nocturnal activity & $\begin{array}{l}\text { Birds - night is the main period a species is active for foraging } \\
\text { Mammals - period a species is active for foraging }\end{array}$ & - & Nocturnal - yes: $1 /$ no: 0 & Wilman et al. (2014) \\
\hline Crepuscular activity** & Period a species is active for foraging & & Crepuscular - yes: 1/no: 0 & Wilman et al. (2014) \\
\hline Diurnal activity** & Period a species is active for foraging & & Diurnal - yes: $1 /$ no: 0 & Wilman et al. (2014) \\
\hline Home range** & Average home range size & $\mathrm{m}^{2}$ & - & $\begin{array}{l}\text { Tamburello et al. (2015); Tucker } \\
\text { et al. (2014) }\end{array}$ \\
\hline Migratory behavior* & Most of the populations exhibit migratory behaviors & & Migratory - yes: $1 /$ no:0 & del Hoyo et al. (2018) \\
\hline Population density & Number of individuals per $\mathrm{km}^{2}$ & $\mathrm{n} \mathrm{km}^{-2}$ & - & $\begin{array}{l}\text { Jones et al. (2009); Santini et al. } \\
(2018)\end{array}$ \\
\hline Sociality** & $\begin{array}{l}\text { Species in which individuals spend most of their time foraging } \\
\text { in a group }\end{array}$ & - & $\begin{array}{l}\text { Social }-1 \\
\text { No social }-0\end{array}$ & $\begin{array}{l}\text { Jones et al. (2009); Myers et al. } \\
(2016)\end{array}$ \\
\hline Diet breadth & $\begin{array}{l}\text { Diversity of each species diet described as the total number of diet } \\
\text { categories consumed considering four possible dietary categories } \\
\text { (fruit/nectar, plant/seed, invertebrate, vertebrate } \\
\text { [amphibian/reptile/bird/mammal/fish/carrion]). Specialists consume a } \\
\text { single category, diet breadth }=1 \text {, while generalists could consume items } \\
\text { from all four with a diet breadth }=4 \text {. }\end{array}$ & - & $1-4$ & Wilman et al. (2014) \\
\hline Scavenger & Percentage of carrion in their diet & $\%$ & - & Wilman et al. (2014) \\
\hline Dominant diet* & Categorical variable of the main diet & & $\begin{array}{l}\text { Fruit/nectar, } \\
\text { invertebrate, } \\
\text { omnivore, } \\
\text { plant/seed, } \\
\text { vertebrate/fish/scavenger }\end{array}$ & Wilman et al. (2014) \\
\hline
\end{tabular}


carnivore,

herbivore,

Mammals - percentage of carnivore and herbivore diet and omnivore

omnivore

\section{Mammals}

$\%$ of carnivore diet,

$\%$ of herbivore diet,

omnivore $-1 / 0$

Ground forager

Binary variable describing species classified as ground foragers that

Ground forager - 1

feed no higher than $2 \mathrm{~m}$ from the ground

Non-ground forager -0

Habitat breadth

Birds - total number of land uses based on the list of terrestrial biomes

and other habitat features (urban/semi-urban, desert/dune,

savanna/grassland, chaparral/bush, forest [tundra, forest, and taiga],

agricultural, riparian/estuarine/intertidal/wetlands/coastal)

Mammals - total number of land uses based on the list of terrestrial

$1-8$

biomes and other habitat features

(urban, semi-urban, desert or dune, savanna or grassland,

chaparral/scrub, scrub/forest, agricultural, riparian)

Open habitats

Preference for open areas (desert, dune, savanna, grassland)

(2)

Preference for closed areas (chaparral, forest, riparian)

Preference for intertidal, wetlands, water, or coastal areas

Open -1

Not open -0

Closed -1

Not closed -0

Water habitats*

Water -1

Absent -0

\section{EXPOSURE TO HUMANS}

Exploitation

Binary descriptor to identify species classified as at risk from direct exploitation based on the International Union for Conservation of

Nature (IUCN; species classified as affected by categories 5.1 and/or

$5.4)$.

\section{DEMOGRAPHIC PARAMETERS}

\section{Clutch/litter size}

Clutches/litters per year

Interval between births

Mortality

\begin{tabular}{llll} 
& & & \\
Number of female offspring produced at one birth & - & - & Myhrvold et al. (2015) \\
\hline Number of litters or clutches produced per year & - & - & Myhrvold et al. (2015) \\
\hline 1/clutch or litter per year & year & - & Myhrvold et al. (2015) \\
\hline 1/longevity & year & - & Myhrvold et al. (2015)
\end{tabular}

\begin{tabular}{ll}
$\begin{array}{l}\text { Direct exploitation }-1 \\
\text { No exploitation }-0\end{array}$ & $\begin{array}{l}\text { IUCN Threats Classification } \\
\text { Schemes, category 5.1 (v3.2). }\end{array}$ \\
& \\
\hline- & Myhrvold et al. (2015) \\
\hline- & Myhrvold et al. (2015) \\
\hline- & Myhrvold et al. (2015) \\
\hline
\end{tabular}

Notes: *exclusive to birds; **exclusive to mammals. Definition and data sources of demographic parameters considered for inclusion in the population models (data regarding maturity age [in years] and longevity were also included in the population models). 


\section{WebReferences}

Del Hoyo J, Elliot A, and Sargatal J. 2018. Handbook of the birds of the world. Vol 1-12. Barcelona, Spain: Lynx Editions; 1992-2007.

IUCN. 2018. The IUCN Red List of Threatened species. Gland, Switzerland: www.iucnredlist.org.

Jones KE, Bielby J, Cardillo M, et al. 2009. PanTHERIA: a species-level database of life history, ecology, and geography of extant and recently extinct mammals. Ecology 90: 2648-48.

Myers P, Espinosa R, Parr CS, et al. 2016. The Animal Diversity Web (online). https://animaldiversity.org. Accessed between May and June 2016.

Myhrvold N, Baldridge E, Chan B, et al. 2015. An amniote life-history database to perform comparative analyses with birds, mammals, and reptiles. Ecol Archives 96: 3109.

Tamburello N, Côté IM, and Dulvy NK. 2015. Energy and the scaling of animal space use. Am Nat 186: 196-211.

Tucker MA, Ord TJ, and Rogers TL. 2014. Evolutionary predictors of mammalian home range size: body mass, diet and the environment. Glob Ecol Biogeog 23: 1105-14.

Wilman H, Belmaker J, Simpson J, et al. 2014. EltonTraits 1.0: species-level foraging attributes of the world's birds and mammals. Ecol Archives 95: 2027. 


\section{Grilo et al. - Supporting Information}

\section{WebPanel 1. Roadkill rate estimation}

A systematic search for scientific papers focusing on road ecology in Europe published in peerreviewed journals and gray literature (eg technical reports, theses, dissertations) was conducted between April and June 2018. We used the search terms ("roadkill" OR "road mortality") AND ("birds" OR "mammals") in Google Search, Science Direct, and Web of Knowledge. From each relevant study, we collected the number of roadkilled individuals for each reported species, the duration of the study, the interval between surveys, the length of the sampled road(s), and latitudinal and longitudinal coordinates as the midway point of road(s) or region surveyed. We estimated the roadkill rates (individuals $\mathrm{km}^{-1} \mathrm{yr}^{-1}$ ) and applied corrections in accordance with survey frequency.

We compiled information on birds from Bulgaria, the Czech Republic, Denmark, Norway, Poland, Portugal, European Russia, Slovakia, and Spain, and on mammals from Austria, Belarus, Belgium, Bulgaria, Croatia, the Czech Republic, Estonia, Finland, France, Germany, Ireland, Italy, Lithuania, Montenegro, Norway, Poland, Portugal, European Russia, Slovakia, Spain, Sweden, and the UK. We applied a correction factor as described by Santos et al. (2011):

\section{Correction factor applied to each study}

\begin{tabular}{|c|c|c|c|c|c|c|c|c|}
\hline Frequency of survey & carnivores & lagomorphs & small mammals & hedgehogs & bats & birds of prey & large birds (>1200gr) & small birds (<1200gr) \\
\hline $1 /$ month & 2.14454 & 9.33048 & 13.76462 & 3.13346 & 22.75660 & 2.89992 & 3.58196 & 14.20372 \\
\hline $2 /$ month & 1.72499 & 4.95260 & 6.89389 & 2.19513 & 11.37830 & 2.02751 & 2.49128 & 7.40792 \\
\hline $3 /$ month & 1.57265 & 3.47754 & 4.69876 & 1.84932 & 7.58550 & 1.71212 & 2.00831 & 5.10754 \\
\hline $5 /$ month & 1.40102 & 2.39313 & 3.05595 & 1.53192 & 4.55130 & 1.45494 & 1.58240 & 3.26595 \\
\hline 1/week & 1.45045 & 2.66000 & 3.46194 & 1.61539 & 5.30990 & 1.51823 & 1.68842 & 3.72087 \\
\hline 2/week & 1.17324 & 1.44971 & 1.59961 & 1.18248 & 2.01140 & 1.18739 & 1.21261 & 1.65433 \\
\hline 3/week & 1.12886 & 1.32279 & 1.42932 & 1.12500 & 1.70870 & 1.14142 & 1.15660 & 1.46162 \\
\hline 1/day & 1 & 1 & 1 & 1 & 1 & 1 & 1 & 1 \\
\hline
\end{tabular}

\section{Selection of birds and mammals, and their geographic ranges}

For each species, we used distribution maps provided by the International Union for Conservation of Nature (IUCN) Red List of Threatened Species (https://www.iucnredlist.org, downloaded October 2018) to generate a list of European birds and mammals. Non-native species and species that had been re-introduced into Europe were excluded from the analysis, as were marine species and birds that primarily inhabit coastal areas. From the IUCN species distribution maps, we considered only the polygons classified as presence ("Extant", "Probably Extant", or "Possible Extant"), origin ("Native", "Reintroduced", or "Introduced"), and seasonality ("Resident", "Breeding Season", "Non-breeding Season”, or "Passage"). We considered all species classified on the IUCN Red List as Near Threatened, Vulnerable, Endangered, and Critically Endangered as Threatened.

\section{Reaction-diffusion equation}

Population dynamics and dispersal were calculated by Skellam (1951) and Borda-de-Água et al. (2011) using the equation: 
$\frac{\partial N(x, y, t)}{\partial t}=\left\{\begin{array}{lr}\frac{\sigma^{2}}{2} \nabla^{2} N(x, y, t)+r_{1} N(x, y, t)\left(1-\frac{N(x, y, t)}{K}\right) & \text { if }(x, y) \notin \text { road } \\ \frac{\sigma^{2}}{2} \nabla^{2} N(x, y, t)+r o N(x, y, t) & \text { if }(x, y) \in \text { road }\end{array}\right.$

(Equation 1),

where $N(x, y, t)$ is the population density in location $(x, y)$ at time $t, \sigma^{2}$ stands for the dispersal variance modeling the dispersal distance of individuals, and $K$ denotes the carrying capacity; the symbol $\nabla^{2}$ stands for $\partial^{2} / \partial x^{2}+\partial^{2} / \partial y^{2}$ (the so-called "Laplace operator"). The first term on the right-hand side of the equation describes the changes in time and space of the density of a population on the basis of its dispersal distance, assuming a Gaussian distribution. The second term on the top branch corresponds to logistic growth (outside roads) and on the bottom branch corresponds to population decay on roads (assumed by a negative growth rate, where $r_{0}<0$; Borda-de-Água et al. 2011). $r_{0}$ is interpreted here as an instantaneous mortality rate when an individual crosses a road, and is a measurement of the loss of individuals from a specific population.

\section{Intrinsic population growth equation $\left(r_{1}\right)$}

A simplified version of the Euler equation (Skellam 1951) was used to estimate $r_{1}$ based on species-specific life-history parameters that included age at first breeding ( $\beta$ ) (year) (we used maturity age instead); interval between births $(\Delta)$ (year); clutch/litter size $(b)$; and the constant mortality rate $(\mu)$ :

$b x \int_{0}^{\infty} \sum_{y=0}^{\infty} \delta(x-y \Delta-\beta) e^{-(11+\mu) x} d x=1$

(Equation 2),

where $\delta(x)$ is the Dirac delta function.

\section{Global sensitivity analysis}

We performed a global sensitivity analysis to determine which model input parameters

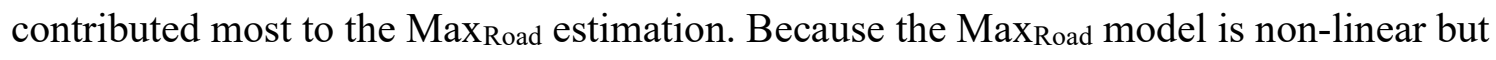
monotonic, we ran a ranked linear regression model with the input variables of Max Road to measure the effects of the parameters across their entire domains (Iooss and Lemaitre 2015).

\section{WebReferences}

Borda-de-Água L, Navarro L, Gavinhos C, and Pereira HM. 2011. Spatio-temporal impacts of roads on the persistence of populations: analytic and numerical approaches. Landscape Ecol 26: $253-65$.

Iooss B and Lemaître P. 2015. A review on global sensitivity analysis methods. In: Meloni C and Dellino G (Eds). Uncertainty management in simulation optimization of complex systems: algorithms and applications. New York, NY: Springer.

Santos SM, Carvalho F, and Mira A. 2011. How long do the dead survive on the road? Carcass persistence probability and implications for road-kill monitoring surveys. PLoS ONE 6: e25383.

Skellam JG. 1951. Random dispersal in theoretical populations. B Math Biol 53: 135-65. 
Raw data included in the repository at https://doi.org/10.6084/m9.figshare.7931423.v2

1 RoadkillBirds.csv - Order, Family, Species, Common name, IUCN status, Roadkill (number of individuals roadkilled), Road length (kms), Period (number of days between the first and last survey), Roadkill rate (ind/km/year), Type of survey, Surveys (number of days of survey), Frequency of survey, Survey interval (interval between surveys (days)), Correction factor (from Santos et al. 2011), Roadkill corrected (Roadkill rate*Correction factor), Latitude (WGS84 decimal degrees), Longitude (WGS84 decimal degrees), Country, Reference 2 RoadkillMammals.csv - Order, Family, Species, Common name, IUCN status, Roadkill (number of individuals roadkilled), Road length $(\mathrm{kms})$, Period (number of days between the first and last survey), Roadkill rate (ind/km/year), Type of survey, Surveys (number of days of survey), Frequency of survey, Survey interval (interval between surveys (days)), Correction factor (from Santos et al. 2011), Roadkill corrected (Roadkill rate*Correction factor), Latitude (WGS84 decimal degrees), Longitude (WGS84 decimal degrees), Country, Reference

3 RoadkillReferences.csv - Complete references of road surveys

4 LifetraitBirds.csv - Life traits of birds (see WebTable 1)

5 LifetraitsMammals.csv - Life traits of mammals (see WebTable 1)

6 LifeTraitsReferences.csv - Complete references of life traits

7 PredictedroadkillratesBirds.csv - Predicted roadkill rates for birds

8 PredictedroadkillratesMammals.csv - Predicted roadkill rates for mammals

9 RankingvulnerableBirds.csv - Rank of vulnerability of birds based on maximum road density estimates $(\mathrm{RM}=1000)$.

10 RankingvulnerableMammals.csv - Rank of vulnerability of mammals based on maximum road density estimates $(\mathrm{RM}=1000)$.

\section{Shapefiles}

Nroadkillgrid50.shp

Road length $-\mathrm{km}$

$\mathrm{km} / \mathrm{km}^{2}-$ road density

BRP_median - median of predicted roadkill rates for birds

BRP_LCI - lower 95\% confidence interval of predicted roadkill rates for birds

BRP_UCI - upper 95\% confidence interval of predicted roadkill rates for birds

BRK_median - total number of roadkills (BRP_median*Road length)

BRK_LCI - total number of roadkills (BRP_LCI*Road length)

BRK_UCI - total number of roadkills (BRP_UCI*Road length)

MRP_median - median of predicted roadkill rates for mammals

MRP_LCI - lower 95\% confidence interval of predicted roadkill rates for mammals

MRP_UCI - upper 95\% confidence interval of predicted roadkill rates for mammals

MRK_median - total number of roadkills (MRP_median*Road length)

MRK_LCI - total number of roadkills (MRP_LCI*Road length)

MRK_UCI - total number of roadkills (MRP_UCI*Road length)

Nvulnerablegrid50.shp

B_N_Species20th - number of vulnerable bird species (within 20th percentile)

B_N_Species - total number of bird species 
B_Prop_20th - Proportion of vulnerable bird species (B_N_Species20th/ B_N_Species) M_N_Species20th - number of vulnerable mammal species (within 20th percentile) M_N_Species - total number of mammal species

M_Prop_20th - Proportion of vulnerable mammal species (M_N_Species20th/ M_N_Species) 